\title{
Gluten challenge in children with dermatitis herpetiformis: a clinical, morphological and immunohistological study
}

\author{
I KÓSNAI, S KÁRPATI, E SAVILAHTI, M VERKASALO, P BUCSKY, \\ E TÖRÖK
}

From the 1st Department of Pediatrics, and 2nd Department of Pathology, Semmelweis University, Budapest. Hungary, Dermatology Department, Heim Pál Children's Hospital, Budapest, Hungary, and the Children's Hospital, University of Helsinki, Helsinki, Finland

SUMmaRY Twenty one children with dermatitis herpetiformis were studied in an attempt to evaluate the response in the skin, in jejunal morphology, and in jejunal immunoglobulin containing cell counts to gluten elimination and subsequent gluten challenge. In all of the 15 patients whose jejunal biopsy was studied after the eventual gluten challenge the jejunal lesion had returned in $2 \cdot 4$ to 28 months. The numbers of IgA- and IgM-containing cells were similarly raised in primary and postchallenge biopsies. In the 13 patients whose skin improved during a gluten free diet and who were challenged with gluten the rash worsened and the dapsone/ sulphapyridine requirement increased. The jejunal deterioration was equally marked in the six patients whose gluten challenge was stopped because of an intractable rash as it was in those who completed the preplanned challenge. The specimens of the former, however, had significantly more IgA-containing cells than specimens of the latter. The number of intraepithelial lymphocytes clearly reflected the degree of intestinal damage. IgA-containing cells proved to be the most sensitive indicator of an immune reaction taking place in the gut of these patients. Even in the two children with initially normal or nearly normal jejunal mucosa, the $\operatorname{IgA}$ cell counts in the jejunal lamina propria were markedly raised.

Dermatitis herpetiformis is characterised by a pruritic polymorphic skin rash comprising of small blisters, papules, macules, and crusts. The diagnosis can be confirmed by an immunofluorescent study of the skin, which shows granular deposits of $\operatorname{IgA}$ in the papillary dermis. ${ }^{1-3}$ It is believed that these immunoglobulin deposits lead to activation of complement, resulting in inflammatory reaction and skin lesion. ${ }^{4}$ The origin of these deposits is not quite clear, but evidently gluten has a central role in their genesis. ${ }^{56}$ The majority of dermatitis herpetiformis patients have an intestinal lesion similar to that of coeliac disease. ${ }^{137}$ Most studies agree that both the intestinal and skin lesions are cured by a strict gluten free diet. ${ }^{398}$ In coeliac disease the permanence of

Address for correspondence: Dr E Savilahti, Children's Hospital, University of Helsinki. SF-(0)290) Helsinki. Finland.

Received for publication 1 April 1986 gluten sensitivity is shown by a challenge test with gluten. ${ }^{10}$ In dermatitis herpetiformis patients there are very few reports on the effect of gluten challenge on the skin and the intestine. 1172

The aim of the present study is to describe the jejunal structure and immunoglobulin containing cells in 21 paediatric patients, 16 of whom were followed through gluten challenge. The clinical picture and the results of gluten free diet treatment of the rash and jejunal morphology of 20 of these children, as well as the gluten challenge of two have been reported previously. ${ }^{3}$

\section{Methods}

PATIENTS

Twenty one children with typical skin lesions and granular deposits of IgA in the papillary dermis of the uninvolved skin (2) were studied (Table). The mean age at the onset of the rash was 5.2 years 
Table 1 The severity of skin symptoms, drug requirements and the jejunal morphology of patients

\begin{tabular}{|c|c|c|c|c|c|c|c|c|c|c|c|c|c|}
\hline & & $\begin{array}{l}\text { Age (yr) } \\
\text { at start }\end{array}$ & Duration & $n(y r)$ & of severity & of skin & symptoms & Drug & requires & nent & Jejunal & orphology & \\
\hline Case & Sex & of $G F D$ & $G F D$ & $G C h$ & $A$ & $B$ & $C$ & $A$ & $\dot{B}$ & $C$ & $A$ & $B$ & $C$ \\
\hline 1 & $\mathrm{~F}$ & $5 \cdot 3$ & $1 \cdot 2$ & 0.2 & ++ & - & + & ++ & - & + & $S V A$ & $P V A$ & $S V A$ \\
\hline 2 & $\mathrm{~F}$ & $2 \cdot 3$ & $1 \cdot 0$ & 0.3 & ++ & - & + & ND & ND & ND & $S V A$ & PVA & $S V A$ \\
\hline 3 & $F$ & $3 \cdot 4$ & $1 \cdot 3$ & $0 \cdot 4$ & ++ & - & + & ++ & - & ++ & $S V A$ & slight & $P V A$ \\
\hline 4 & $\mathrm{~F}$ & $10 \cdot 0$ & $1 \cdot 6$ & 0.5 & ++ & - & + & ++ & - & + & $P V A$ & slight & $S V A$ \\
\hline 5 & $\mathrm{~F}$ & $5 \cdot 5$ & $1 \cdot 1$ & 0.4 & ++ & - & ++ & ++ & - & ++ & SVA & PVA & SVA \\
\hline 6 & $\mathrm{~F}$ & $8 \cdot 3$ & $1 \cdot 2$ & $0 \cdot 3$ & ++ & - & + & ++ & - & + & SVA & slight & SVA \\
\hline 7 & $\mathrm{~F}$ & $11 \cdot 4$ & $1 \cdot 0$ & $0 \cdot 2$ & ++ & - & + & ND & ND & ND & $S V A$ & normal & ND \\
\hline 8 & $\mathrm{~F}$ & $5 \cdot 1$ & 0.9 & 0.5 & ++ & ++ & ++ & ++ & ++ & ++ & $S V A$ & $P V A$ & $S V A$ \\
\hline 9 & $\mathrm{~F}$ & $6 \cdot 1$ & $3 \cdot 7$ & $1 \cdot 5$ & ++ & - & + & ++ & - & - & SVA & slight & $S V A$ \\
\hline 10 & M & $4 \cdot 3$ & 1.9 & 0.9 & ++ & + & ++ & ++ & + & ++ & PVA & slight & $S V A$ \\
\hline 11 & M & $6 \cdot 3$ & $1 \cdot 1$ & $2 \cdot 4$ & ++ & ++ & ++ & ++ & ++ & ++ & SVA & normal & $S V A$ \\
\hline 12 & $\mathbf{M}$ & $10 \cdot 2$ & $1 \cdot 0$ & 0.4 & ++ & + & ++ & ++ & - & ++ & SVA & normal & PVA \\
\hline 13 & $\mathrm{~F}$ & 6.9 & 1.0 & $1 \cdot 1$ & ++ & ++ & ++ & ++ & ++ & ++ & $P V A$ & normal & SVA \\
\hline 14 & $\mathrm{~F}$ & $3 \cdot 7$ & $1 \cdot 0$ & $0 \cdot 3$ & ++ & + & ++ & ++ & + & ++ & PVA & slight & SVA \\
\hline 15 & $M$ & 1.7 & 1.7 & 0.5 & ++ & + & ++ & ++ & - & - & SVA & slight & SVA \\
\hline 16 & $\mathrm{~F}$ & $13 \cdot 3$ & $1 \cdot 0$ & 0.5 & ++ & - & + & ++ & - & - & SVA & slight & SVA \\
\hline 17 & $F$ & $7 \cdot 0$ & $3 \cdot 7$ & ND & ++ & - & ND & ++ & - & ND & $P V A$ & normal & ND \\
\hline 18 & $F$ & $6 \cdot 9$ & $1 \cdot 0$ & ND & ++ & ++ & ND & ++ & ++ & ND & $P V A$ & slight & ND \\
\hline 19 & $F$ & $2 \cdot 8$ & & ND & ++ & ++ & ND & ++ & + & ND & $P V A$ & ND & ND \\
\hline 20 & M & $14 \cdot 4$ & ND & ND & ++ & ND & ND & ++ & ND & ND & slight & ND & ND \\
\hline 21 & $\mathrm{M}$ & $9 \cdot 2$ & ND & ND & ++ & ND & ND & ++ & ND & ND & normal & ND & ND \\
\hline
\end{tabular}

In patients $1-7$ the gluten challenge was stopped because of skin symptoms.

A - at the time of initial jejunal biopsy, during gluten containing diet, B - after the gluten free diet, $\mathrm{C}-$ after gluten challenge. Specimens used for immunohistochemical study are italicised.

SVA - median height of the villi less than $150 \mu$. PVA median height of the villi $12(1-250) \mu$.

Slight changes - median height of the villi $250-300) \mu$.

Normal - median height of the villi more than $300 \mu \mu$.

The severity of the skin symptoms was graded..+++-

The amount of drug used was graded,,+++- .

Sulfone was used in cases $3,9,10,11,12,14,17,19,20,21$

Sulphapyridine was used in cases $1,4,5,6,8,13,15,16,18$

(range 1.5 to $12 \cdot 0$ ), and there were 15 girls and six boys.

An immunohistochemical examination could be performed on 29 jejunal biopsies of 15 patients (Table), in the others the biopsy material was not sufficient or available. In four specimens the staining of immunoglobulin containing cells was unsuccessful, probably because of denaturation of immunoglobulins during the processing of the biopsy specimens.

Controls for the study included children in whom a jejunal biopsy was performed because of delayed growth, and who did not have intestinal symptoms or any signs of gastrointestinal disease. The results for the 17 controls of the morphometric study whose mean age was 4.6 years have been reported previously. ${ }^{13}$ Another control group of 10 children with mean age of 8.2 years was studied for the immunohistochemical part of the study.

TREATMENT

Initially 19 patients were treated with dapsone or sulfapyridine (Table). After establishment of the minimum dose required to control the rash, gluten free diet was started in 17 patients; two (cases 20 and 21) did not start on the diet. Cases 2 and 7 refused to take the drugs, but were put on gluten free diet. During the diet period the drug dose was reduced, if possible. The response of the jejunal structure to gluten free diet was studied in patients having initially a total or partial villous atrophy of the jejunum (cases 1-18), case 19 refused further biopsies. The mean duration of the gluten free diet was 1.5 years, ranging from 0.9 to 3.7 years. The effect of gluten challenge was then studied in cases 1-16; patients were instructed to resume their normal pretreatment dietary habits for five to 13 months, after which a control jejunal biopsy was taken. Case 7 refused the follow up biopsy. In cases 1-6, a biopsy was carried out owing to the deterioration of the skin. Cases 9 and 11 showed neither deterioration of jejunal mucosa nor recurrence of the skin lesion after a challenge of eight and six months, and gluten challenge was continued until 
reappearance of the rash in case 9 for a total of 1.5 years and in case 11 for 2.4 years. Both had mucosal relapse at that time. The parents of the patients gave informed consent to the study.

Jejunal biopsy samples were taken from the proximal jejunum at the level of ligament of Treitz with a two port Crosby capsule of paediatric size. The specimens for intestinal morphometry were processed and examined as described previously. ${ }^{13}$ The number of intraepithelial lymphocytes was expressed per 100 epithelial cells. ${ }^{13}$ Eosinophilic cells in the lamina propria were counted using $1000 \times$ magnification and their numbers expressed per square millimetre. ${ }^{14} \mathrm{IgA}-, \mathrm{IgG}$ - and IgM-containing cells were examined by the direct immunoperoxidase technique and counted per $\mathrm{mm}^{2}$ of lamina propria as described previously. ${ }^{15}$ The measurements of patients were compared with those from controls using the Student's $t$ test, and only preplanned comparisons were performed. The distribution of data was tested for normality using normal

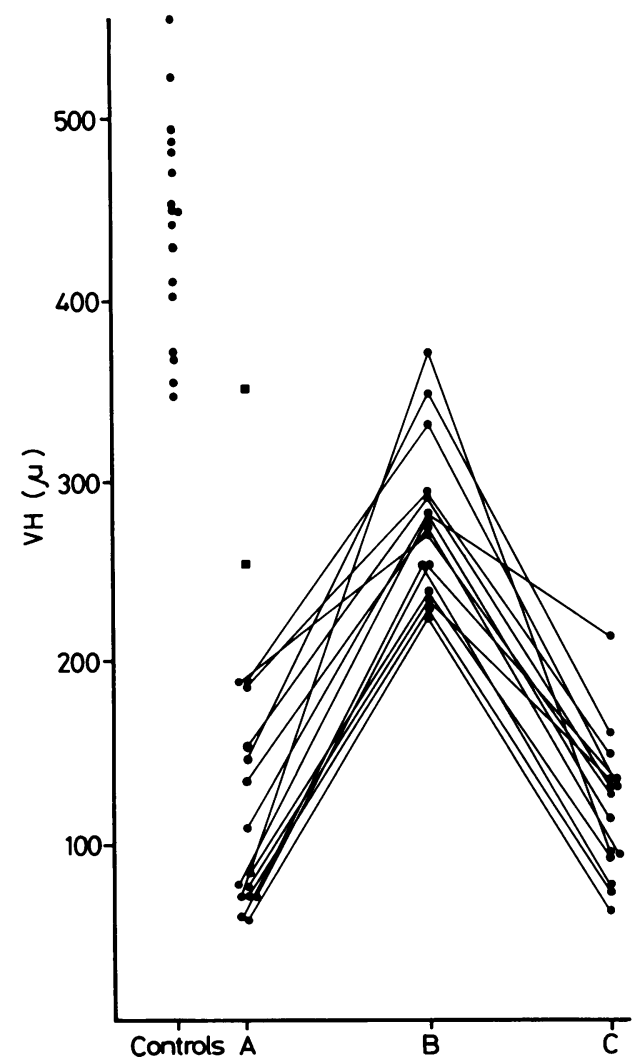

Fig. 1 The heights of the villi in specimens of controls and of patients initially $(A)$, after $G F D(B)$ and after the $G C h$ (C). Two patients with normal or slightly reduced heights of the villi are indicated ( $\square$ ). probability plots. ${ }^{16}$ Values for immunoglobulin containing cells were skewed. This distribution was normalised by logarithmic transformation, which was used in calculations. An analysis of variance for repeated measurements ${ }^{16}$ was used to compare measurements from the same patients at various stages of dietary treatment.

\section{Results}

RESPONSE OF THE SKIN TO GLUTEN ELIMINATION AND CHALLENGE

All of the patients had a marked rash during normal diet. After establishment of the minimum effective dose of dapsone or sulphapyridine, gluten free diet was instituted. After gluten free diet, which averaged 17.6 months, 10 patients reported complete disappearance, and four marked alleviation of the rash. The drug could be discontinued for 10 patients and the dose reduced for three. Gluten challenge resulted in the reappearance of the rash in nine, and in exacerbation in four children; the drug had to be restarted in six and the dose increased in two patients (Table).

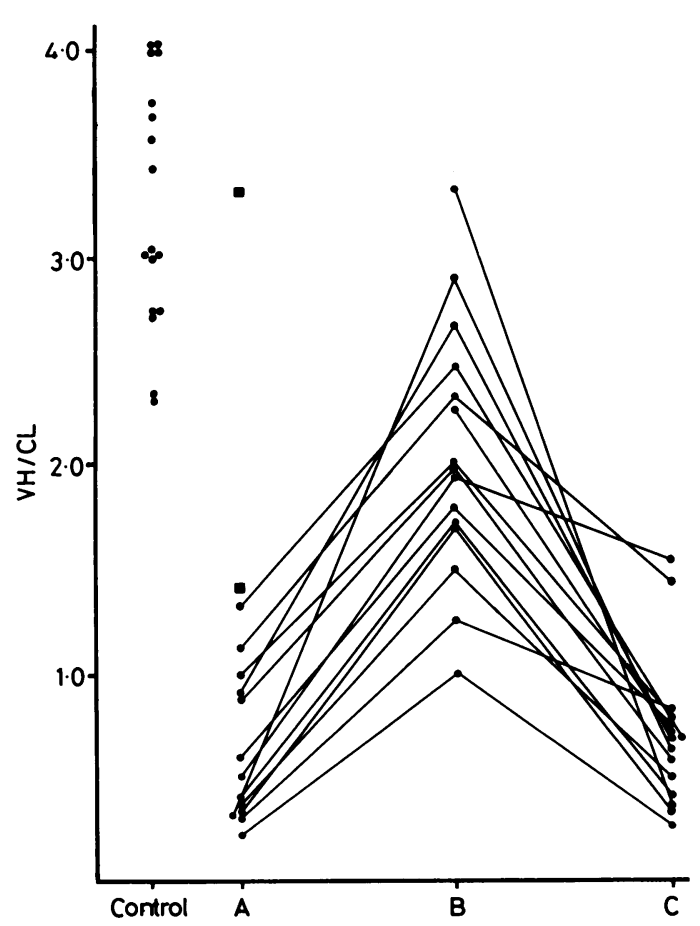

Fig. 2 Ratios of villus heights to crypt lengths in the jejunal specimens of patients and controls. Symbols as in Fig. 1. 


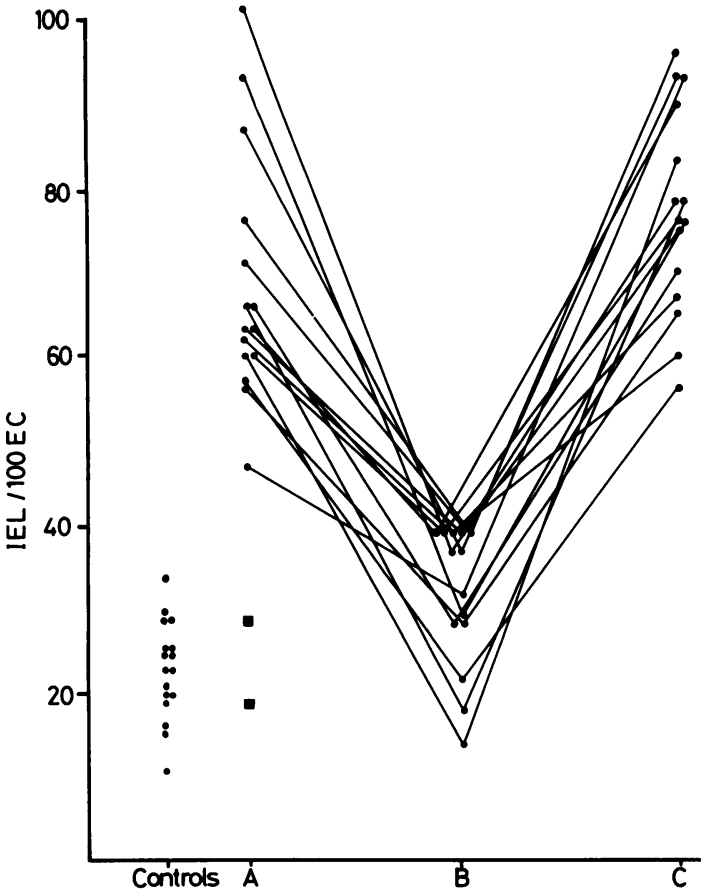

Fig. 3 Numbers of intraepitheial lymphocytes of patients and controls. Symbols as in Fig. 1.

JEJUNAL MORPHOMETRY

Figures 1-4 give the data for villus heights, the villus height to crypt depth ratios, the numbers of intraepithelial lymphocytes and the numbers of lamina propria eosinophils in the jejunal biopsy specimens from patients at different stages of treatment and from the controls. Initially, cases 20 and 21 had only minor changes in the villus structure and normal numbers of intraepithelial lymphocytes (Figs 1-4). They had no further biopsies. In the others, the normalisation of the jejunal mucosa became normal with a gluten free diet. All the cited measurements in biopsy specimens taken before any treatment and after gluten challenge differed highly significantly $(\mathrm{p}<0.0001)$ from the measurements in specimens taken after gluten free diet or from measurements in the control specimens, and only the increase in the numbers of eosinophils was less significant $(p<0 \cdot 01)$. The jejunal damage was equally severe before the gluten free diet and after gluten challenge. The mean values of morphometric measurements from patients whose gluten challenge was stopped because of skin symptoms were similar to measurements from the other patients (mean villus height: $126 v s 114 \mu \mathrm{m}$;

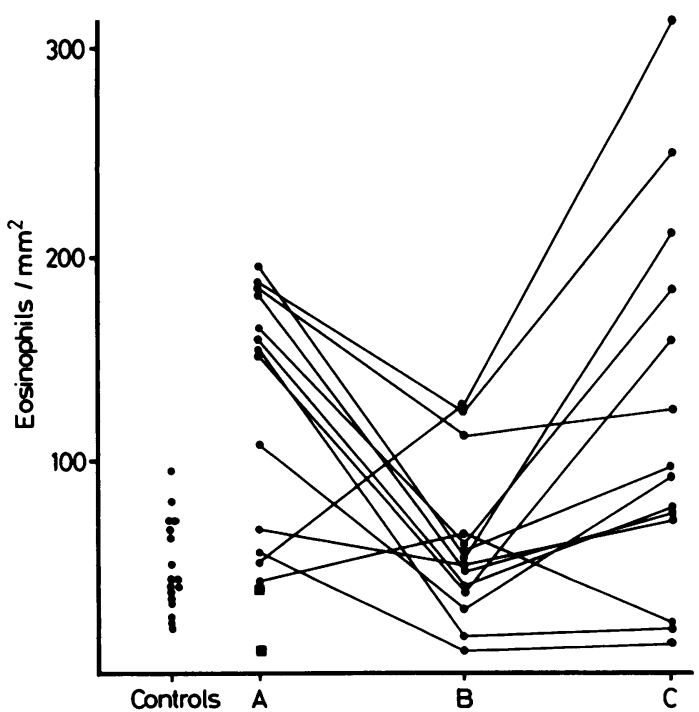

Fig. 4 Numbers of eosinophils in the lamina propria of jejunal biopsy specimens of patients and controls. Symbols as in Fig. 1.

mean ratio of villus height to crypt depth $0.75 \mathrm{vs}$ 0.60 ; mean number of intraepithelial lymphocytes 77 vs 142 cells $\mathrm{m} / \mathrm{mm}^{2}$ ). In three patients (cases 8 , 11 , and 13) whose rash and drug requirement remained unchanged during the dietary treatment and challenge, the jejunal damage was as pronounced as in the other patients. Cases 11 and 9 had a slow relapse: jejunal morphology and the rash were unchanged after 5.5 and eight months of gluten challenge, but after a total of 30 and 18 months of gluten challenge there was a clear jejunal relapse in both, and reappearance of the rash in case 9 , in whom gluten free diet had brought about a skin remission.

\section{IMMUNOGLOBULIN-CONTAINING CELLS}

Before the dietary treatment numbers of both $\operatorname{IgA}$ and IgM-containing cells (Figs 5 and 6 ) in the lamina propria of the jejunum were significantly higher in the specimens of the patients than in control specimens $(p=0.0002$ and 0.0001 respectively). All values for $\operatorname{IgA}$-containing cells of patients were higher than any of the controls irrespective of the morphometric grading of the biopsy specimens (Fig. 5); the lowest value for IgM cells was seen in the specimen with only slight villus height reduction and this number was within the normal range (Fig. 6). During gluten free diet the cell numbers fell significantly, but remained higher than those of the controls ( $p$ for IgA 0.04 and for IgM 0.04). 


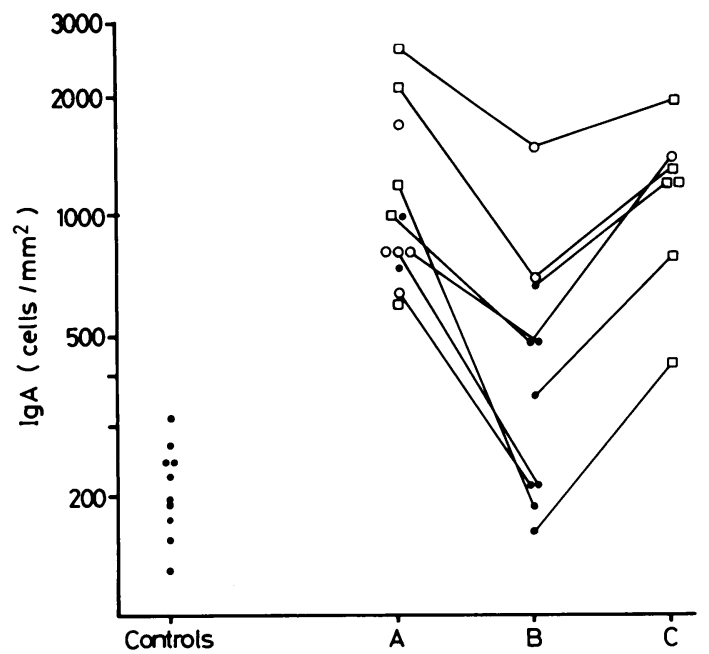

Fig. 5 Numbers of IgA-containing cells in the lamina propria of the jejunum of patients and controls. Symbols $A, B$ and $C$ as in Fig. I. $\square=$ specimens showing (sub)total villus atrophy. $\mathrm{O}=$ specimens showing partial villus atrophy, =specimens with normal or slightly reduced villus heights. The scale is logarithmic.

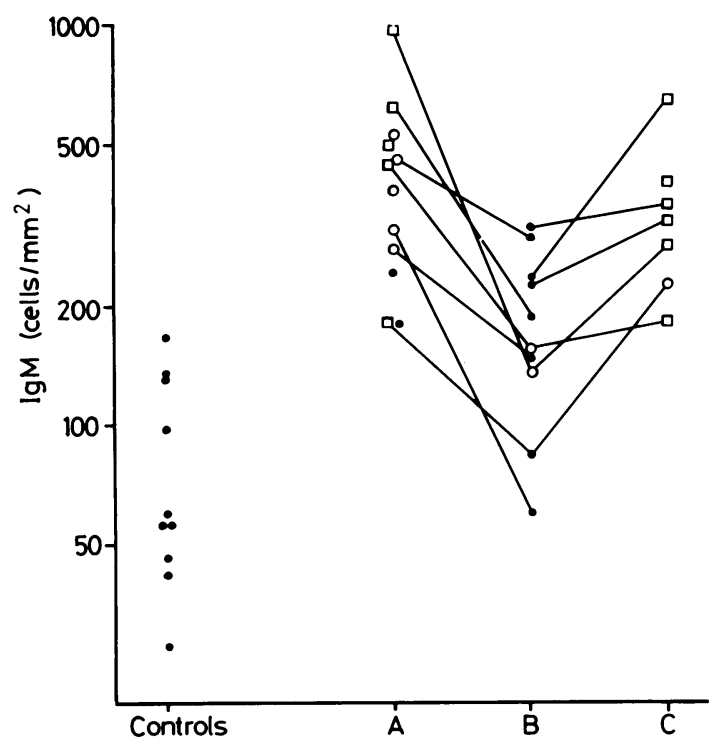

Fig. 6 Numbers of IgM-containing cells in the lamina propria of patients and controls. Symbols as in Fig. 5.

In the postchallenge biopsies the numbers of $\operatorname{IgA}$ and IgM-containing cells were again significantly raised as compared with those of the controls ( $p=0.002$ and 0.003 , respectively), and comparable with those observed before gluten free diet (geometric mean for IgA-cells before treatment 1070 , after gluten challenge 1121; for IgM-cells 376 and 317). In specimens from three patients whose gluten challenge was stopped because of skin symptoms, more IgA-containing cells were present (logarithmic mean $1542 / \mathrm{mm}^{2}$ ) than in four specimens of patients whose challenge was terminated as scheduled (mean $883)$. The difference between these two groups is significant $(p=0 \cdot 048)$.

\section{Discussion}

The gluten challenge of gluten free diet treated children with dermatitis herpetiformis resulted in reappearance or exacerbation of the rash in all of the 13 patients whose skin had improved during gluten free diet. In previous reports on adults 611 is gluten challenge resulted in exacerbation of the rash in 19 of 24 patients. In this study we could not observe spontaneous remissions, as has been reported for adults. ${ }^{6}$ The crucial question in defining a 'spontaneous remission' in dermatitis herpetiformis patients taking gluten free diet is to determine the length of gluten challenge necessary to prove the extinction of the gluten sensitivity. Leonard $e t a l^{\circ}$ regarded a patient without a relapse after one year of gluten challenge as being in spontaneous remission. One of our patients was symptom free after eight months of gluten challenge, but showed an unequivocal relapse 10 months later. In coeliac disease patients jejunal mucosal damage has been observed to appear years after resuming a gluten containing diet. ${ }^{17}$ As the genesis of dermatitis herpetiformis and coeliac disease is in all probability immunological, the study of the patients with a slow relapse may offer important clues to the immunoregulatory mechanisms involved in the pathogenesis of these diseases. For clinicians responsible for the treatment of dermatitis herpetiformis patients, information from patients who react slowly to the reintroduction of gluten is important: the follow up of dermatitis herpetiformis patients in a spontaneous remission should last for several symptom free years.

Two of our patients had normal or nearly normal jejunal histology. The possibility of patchy intestinal lesion ${ }^{7}$ exists, but is diminished by the use of two port biopsy instrument. They were, at the time of the study, not put on gluten free diet, as the rash was controlled with drugs. In the remaining patients the jejunal morphology improved during gluten free diet and deteriorated during the subsequent gluten challenge, even in those three whose rash did not respond to gluten free diet. This finding also shows the importance of dietary treatment in patients whose skin does not seem to improve from diet. Furthermore, our findings indicate that the rash and 
the intestinal damage are both results of gluten ingestion, but neither is a prerequisite to the other. In the seven patients in this study, whose gluten challenge was discontinued because of exacerbation of the rash, the average duration of the challenge was 18 weeks, as compared with 34.5 weeks for the whole study group. In these patients, nevertheless, the intestinal damage was quite comparable to the rest of the study group. Leonard et al" challenged their patients for an average of 11.9 weeks, and observed skin relapse in 11 of their 12 patients.

The number of intraepithelial lymphocytes has been shown to reflect the extent of the involvement of cell mediated immunity in the reaction of the gut immune system. ${ }^{18}$ In this study the numbers of intraepithelial lymphocytes and the degree of jejunal damage were in good correlation with each other, exemplified by the fact that in the two patients with nearly normal initial jejunal biopsy the numbers of IEL were within the range of the controls.

The role of the eosinophils in the cellular infiltrate in the jejunal lamina propria of these patients remains obscure. The eosinophilic cells may be attracted by immune complexes in jejunal mucosa, or by lymphokines liberated in cell-mediated immune reactions. ${ }^{19}$ Considering our finding of low lamina propria eosinophils in patients with nearly normal jejunal mucosa and low IEL counts, but considerable numbers of IgA-containing cells, the principal factor attracting eosinophils could well be the cell-mediated immune reaction in the gut.

We found a marked increase in IgA- and IgMcontaining cells in the jejunal mucosa of patients before gluten elimination. In every patient, the number of $\operatorname{IgA}$-containing cells was observed to be above the range of the controls. The mean number of IgM-cells was even more distinctly raised, but there was some overlap between the patients and the controls. These findings are in accord with other recent reports ${ }^{20-22}$ and in contrast with an earlier report of increase in only IgG- and IgM-containing cells. ${ }^{23}$ The $\operatorname{IgA}$ reaction seems to be closely related to the development of the rash in dermatitis herpetiformis: in the two patients with initially nearly normal mucosa with normal amounts of IEL and eosinophils, the numbers of IgA-containing cells were nevertheless raised, and in the children with marked deterioration of the rash during gluten challenge, $\operatorname{IgA}$ cells were also more numerous than in those with less pronounced skin symptoms. The $\operatorname{IgA}$ in the skin of dermatitis herpetiformis patients is dimeric, and thus originates in secretory cells. ${ }^{24}$ The antigen of these secretory antibodies is not known. The IgA cell reaction in dermatitis herpetiformis seems to be more persistent than that observed in coeliac disease: of seven coeliac disease patients four had normal amounts of $\operatorname{IgA}$ cells within the range of the controls after only four months on gluten free diet, ${ }^{25}$ whereas only four of 10 dermatitis herpetiformis patients in this study showed jejunal IgA cells within the range of controls after a gluten free diet which averaged $17 \cdot 6$ months. This slow reduction in $\operatorname{Ig}$ A cell numbers may be a reason for the rather long time required for the rash to respond to gluten free diet. Another reason for the slow response in the skin could be that the $\operatorname{Ig} \mathrm{A}$ is strongly bound to the dermis and even in vitro it is dissolved only with great difficulty. ${ }^{26}$ We feel, however, that the most important reason for the ineffectiveness of gluten free diet in inducing remission in both dermatitis herpetiformis and coeliac disease is failure to keep a strict diet, a factor very difficult to compare from one study to another.

It can be speculated that IgM antigluten antibodies synthesised in the intestine in both dermatitis herpetiformis and coeliac disease are particularly important in reactions leading to intestinal epithelial cell destruction, as these antibodies seem to be produced by large numbers of cells but they are neither seen in the circulation of patients nor in skin deposits of dermatitis herpetiformis patients.

The numbers of IgG-containing cells in jejunal biopsy specimens of our patients were increased neither before gluten free diet nor after gluten challenge. It has been speculated that IgG cells are activated to increase only when the first line of defence by $\operatorname{IgA}$ and $\operatorname{IgM}$ cells is overwhelmed. ${ }^{22}$ This could explain why we observed relatively lower amounts of $\mathrm{IgG}$ cells than the amounts observed in some studies on adults ${ }^{23}$; a shorter duration of the disease leaves the first line defence intact although activated.

This study was carried out under the FinnishHungarian scientific collaboration programme. MV and ES received financial support from the Sigrid Jusélius Foundation.

\section{References}

1 Marks J, Shuster S, Watson AJ. Small bowel changes in dermatitis herpetiformis. Lancet 1966; 2: 1280-2.

2 Marsden RA, McKee PH, Bhogal B, Black MM, Kennedy LA. A study of benign chronic bullous dermatosis of childhood and comparison with dermatitis herpetiformis and bullous pemphigoid occurring in childhood. Clin Exp Dermatol 1980; 5: 159-72.

3 Reunala T, Kósnai I, Kárpáti S, Kuitunen P. Török E, Savilahti E. Dermatitis herpetiformis: jejunal findings and skin response to gluten free diet. Arch Dis Child 1984: 59: 517-22. 
4 Mohammed I, Holborow EJ, Fry L, Thompsom BR, Hoffbrand AV, Stewart JS. Multiple immune complexes and hypocomplementaemia in dermatitis herpetiformis and coeliac disease. Lancet 1976; 2: 729-34.

5 Fry L, Keir P, McMinn RMH, Cowan JD, Hoofbrand AV. Small intestinal structure and function and haematological changes in dermatitis herpetiformis. Lancet 1967; 2: 729-34.

6 Leonard J, Haffenden G, Tucker W, et al. Gluten challenge in dermatitis herpetiformis. $N$ Engl $J$ Med 1983; 308: 816-9.

7 Gawkrodger DJ, Blackwell JN, Gilmour HM, Rifkind EA, Heading RC, Barnetson RSt. Dermatitis herpetiformis: diagnosis, diet and demography. Gut 1984; 25: $151-7$.

8 Reunala T, Blomquist K, Tarpila S, Halme H, Kangas $\mathrm{K}$. Gluten-free diet in dermatitis herpetiformis. I. Clinical response of skin lesions in 81 patients. $\mathrm{Br} J$ Dermatol 1977; 97: 473-80.

9 Fry L, Leonard JN, Swain F, et al. Long term follow-up of dermatitis herpetiformis with and without dietary gluten withdrawal. Br J Dermatol 1982; 107: 631-40.

10 Meeuwisse GW. Diagnostic criteria in coeliac disease. Acta Paediatr Scand 1970; 59: 461-3.

11 Fry L, McMinn RHM, Cowan JD, Hoffbrand AV. Gluten-free diet and reintroduction of gluten in dermatitis herpetiformis. Arch Dermatol 1969; 100: 129-35.

12 Blackwell Jn, Barnetson RStC, Gilmour HM, Ferguson $\mathrm{A}$, Heading RC. Does gluten cause the enteropathy and the skin lesion in dermatitis herpetiformis (DH)? [Abstract]. Gut 1980; 21: A923.

13 Kuitunen P, Kósnai I, Savilahti E. Morphometric study of the jejunal mucosa in various childhood enteropathies with special reference to intraepithelial lymphocytes. J Pediatr Gastroenterol Nutr 1982; 1: 525-31.

14 Kósnai I, Kuitunen P, Savilahti E, Sipponen P. Mast cells and eosinophils in the jejunal mucosa of patients with intestinal cow's milk allergy and celiac disease in childhood. J Pediatr Gastroenterol Nutr 1984; 3: 368-72.
15 Perkkiö M, Savilahti E. Time of appearance of immunoglobulin-containing cells in the mucosa of the neonatal intestine. Pediatr Res 1980; 14: 593-5.

16 Dixon WJ. EMDP statistical software 1981. University of California Press, Berkeley, Ca: Department of Biomathematics, 1981.

17 McNicholl B, Egan-Mitchell B, Fottrell PE. Variability of gluten tolerance in treated childhood coeliac disease. Gut 1979; 20: 126-32.

18 Ferguson A, MacDonald TT; McClure JD, Holden RJ. Cell-mediated immunity to gliadin within the small intestinal mucosa in coeliac disease. Lancet 1975; 1: $895-7$.

19 Wasserman SI. The mast cell and the inflammatory response. In: Edwards AM, Pepys J, eds. The mast cell. Tunbridge Wells; Pitman Medical, 1979, 9-20.

20) Lancaster-Smith M, Joyce S, Kumar P. Immunoglobulins in the jejunal mucosa in adult coeliac disease and dermatitis herpetiformis after the reintroduction of dietary gluten. Gut 1977; 18: 887-91.

21 Harrington ChI, Read NW. Dermatitis herpetiformis: effect of gluten-free diet on skin IgA and jejunal structure and function. $\mathrm{Br}$ Med J 1977; 1: 872-5.

22 Baklien K. Fausa O, Thune PO, Gjone E. Immunoglobulins in jejunal mucosa and serum from patients with dermatitis herpetiformis. Scand J Gastroenterol 1977; 12: $161-8$.

23 Lancaster-Smith M, Kumar P, Marks R, Clark ML, Dawson AM. Jejunal mucosal immunoglobulincontaining cells and jejunal fluid immunoglobulins in adult coeliac disease and dermatitis herpetiformis. Gut 1974; 15: 371-6.

24 Unsworth DJ, Payne AW, Leonard JN, Fry L, Holborow EJ. IgA in dermatitis herpetiformis skin is dimeric. Lancet 1982; 1: 478-80.

25 Savilahti E. Intestinal immunoglobulins in children with coeliac disease. Gut 1972; 13: 958-64.

26 Katz SI, Strober W. The pathogenesis of dermatitis herpetiformis. J Invest Dermatol 1978; 70: 63-75. 